\title{
Uma abordagem integral para Saneamento Ecológico em Comunidades Tradicionais e Rurais
}

\author{
An integral approach of ecological sanitation in traditional \\ and rural communities
}

Gustavo Carvalhaes Xavier Martins Pontual Machado (https://orcid.org/0000-0001-5782-3698) ${ }^{1}$

Tania Maria de Freitas Barros Maciel (https://orcid.org/0000-0002-9315-2702) ${ }^{2}$

Michel Thiollent (https://orcid.org/0000-0002-6641-2767) ${ }^{3}$

${ }^{1}$ Núcleo Interdisciplinar para o Desenvolvimento Social, Universidade Federal do Rio de Janeiro (UFRJ). Centro de Tecnologia/ Sala ABC112, Cidade Universitária. 21941-909 Rio de Janeiro RJ Brasil. gustavoxmartins@ gmail.com

${ }^{2}$ Programa de PósGraduação em Psicossociologia de Comunidades e Ecologia Social, UFRJ. Rio de Janeiro RJ Brasil.

${ }^{3}$ Programa de PósGraduação em

Administração, Unigranrio. Rio de Janeiro RJ Brasil.

\begin{abstract}
This article presents an integral approach to work in community projects, based on Guattari's three ecologies and its dialogue with psychosocial theorists, since it involves the need to combine technological interventions with social approaches. These contributions are explored to point out the need for dialogue in the implementation of sanitation actions, mainly in the rural area and in traditional communities, involving the individual, the groups served and their territorial culture. The approach presented was implemented in a joint action with the Caiçara Community of Praia do Sono and the Forum of Traditional Communities of Angra dos Reis, Paraty and Ubatuba (FCT), based on the Observatory of Sustainable and Healthy Territories of Bocaina (OTSS / Fiocruz). It could be verified that the inclusion of the actors in the social mobilization for the sanitation can entail an effective social participation that generates both a subjective change in the conscience of the diverse local actors and structural gains that promote health and quality of life. The panorama covered shows the importance of a global understanding of the problem, but also, of a simultaneous local, territorialized action, adapted to each reality through genuine dialogue and horizontal participation.
\end{abstract}

Key words Ecological sanitation, Knowledge ecology, Traditional communities
Resumo Este artigo apresenta uma abordagem integral para atuar em projetos comunitários, baseada nas três ecologias de Guattari e do seu diálogo com teóricos da psicossociologia, por envolver a necessidade de conjugar intervenções tecnológicas com abordagens sociais. Explora-se essas contribuições para apontar a necessidade do diálogo na implementação de ações de saneamento, principalmente na zona rural e em Comunidades Tradicionais, envolvendo o indivíduo, os grupos atendidos e sua cultura territorial. A abordagem apresentada foi implementada em uma pequisa -ação, junto com a Comunidade Caiçara da Praia do Sono e o Fórum de Comunidades Tradicionais de Angra dos Reis, Paraty e Ubatuba (FCT), a partir do projeto Observatório de Territórios Sustentáveis e Saudáveis da Bocaina (OTSS/Fiocruz). Pode-se constatar que a inclusão dos atores na mobilização social para o saneamento pode estabelecer uma participação social efetiva, que gere tanto uma mudança subjetiva na consciência dos diversos atores locais, como ganhos estruturais que promovam saúde e qualidade de vida. O panorama abordado mostra a importância de uma compreensão global do problema, mas também, simultaneamente, uma atuação local, territorializada, adaptada a cada realidade por meio do diálogo genuíno e uma participação horizontal.

Palavras-chave Saneamento ecológico, Ecologia de saberes, Comunidades tradicionais 


\section{Introdução}

Esta discussão apresenta uma abordagem integral para atuar em projetos comunitários baseada nas três ecologias ${ }^{1}$ e no seu diálogo com teóricos da psicossociologia, com intuito de estabelecer uma proposta que embase o desenvolvimento de atuações nesse campo que considerem além da natureza, os seres humanos em suas formações sociais e questões subjetivas.

No âmbito das políticas públicas ambientais nas zonas rurais e em Comunidades Tradicionais, uma questão fundamental é atender ao compromisso da mobilização social e da educação ambiental para aplicar ações efetivas e eficientes, na direção de uma participação social inclusiva. No campo do saneamento, especificamente, as iniciativas públicas e privadas de implantação de alternativas exógenas pré-definidas a partir de conhecimentos impostos, sem considerar o diálogo com as comunidades atendidas e a sabedoria local, normalmente apresentam resultados insatisfatórios para todos os envolvidos, sejam os promotores ou os beneficiários da ação. Logo, se os processos participativos representam ao mesmo tempo uma necessidade e um desafio no âmbito das ações públicas, são fundamentais a reflexão e o estabelecimento de diferentes interpretações para o desenvolvimento de novas abordagens. Segundo Guattari ${ }^{1}$, há um paradoxo lancinante entre o desenvolvimento contínuo de novas tecnologias com potencialidade de resolver os problemas ecológicos e, por outro lado, a incapacidade das forças sociais organizadas e das formações subjetivas constituídas para se apropriarem desses meios em seus territórios com consciência.

Assim, deve-se refletir sobre ações de saneamento que contemplem uma articulação ético -política, denominada de ecosofia ${ }^{1}$, entre os três registros ecológicos: o da natureza, o das relações sociais e o da subjetividade humana. Para Guattari ${ }^{1}$, é do lado das ciências "duras" que se espera uma reviravolta a respeito dos processos de subjetivação. A partir dessa visão, pode-se conjecturar ações que contemplem tanto a natureza quanto a conscientização dos atores sociais para a promoção da saúde, percebendo esses, não apenas como receptores, mas como parte integrante e integradora da tecnologia em seus territórios. Para o envolvimento dos indivíduos deve-se focar no estímulo ao questionamento, como abordado por Paulo Freire ${ }^{2}$ no campo da educação. Através da práxis, de uma ação-reflexão, ou seja, de uma atuação consciente, os homens e as mu- lheres de cada território podem assumir seu papel de sujeitos e lutar por seus direitos ${ }^{2}$.

O presente estudo se propõe a difundir estratégias para uma abordagem integral no saneamento, alinhada com mecanismos de interação e diálogo com destino ao desenvolvimento de projetos que promovam impactos positivos no território abrangido, tecnologicamente, ecologicamente, socialmente, economicamente e individualmente.

\section{Saneamento e promoção da saúde}

Considerando as evidências atuais de desequilíbrio ecológico, mudanças climáticas, desastres ambientais e o aumento das desigualdades sociais, torna-se evidente a insustentabilidade do modo hegemônico de produção e consumo estabelecido ${ }^{3}$. Nesse contexto de ruptura e de multiplicação dos antagonismos urgem as questões ecológicas, as quais demandam uma problematização que se torna transversal às outras linhas de fratura das formas de relacionamento social, requerendo o estabelecimento de novos paradigmas, por meio de ações contra-hegemônicas ${ }^{1}$.

O desenvolvimento da Agenda 2030, pós2015, e os Objetivos de Desenvolvimento Sustentável (ODS) destacam a inclusão da sustentabilidade como uma dimensão crítica em todas as áreas do conhecimento e campos de ação ${ }^{4}$. Na promoção da saúde, a pactuação do ODS 6, que propõe a garantia da gestão sustentável da água e saneamento para todos, mostra o estreitamento da relação saúde-saneamento em um contexto amplo, como estratégia para aumentar a equidade global ${ }^{5}$ e promover qualidade de vida, já que o saneamento ambiental é considerado um direito universal ${ }^{4}$. A importância de garantir esse direito é comprovada através de estudos epidemiológicos sobre o saneamento, publicados na literatura especializada, nos quais afirma-se, com segurança, que intervenções em abastecimento de água e esgotamento sanitário provocam impactos positivos em diversos indicadores de saúde ${ }^{6}$.

No entanto, no Brasil, a dispersão populacional e a dificuldade de acesso em muitas comunidades e assentamentos rurais trazem complexidade ao atendimento deste direito a uma parte da população, a qual já apresenta maior vulnerabilidade ${ }^{7}$. Ainda, na história da Saúde Pública há relatos sobre as dificuldades de técnicos em saneamento e saúde, em zonas rurais ou bairros periféricos no início do século XX para conseguir a adesão dos moradores nas diversas construções de instalações sanitárias ${ }^{8}$, geralmente por ações 
exógenas pré-determinadas que não respeitam o contexto local.

Logo, é importante uma reflexão e atuação mais profunda no âmbito do saneamento, que contemple os diversos atores envolvidos, promovendo sustentabilidade, equidade e autonomia. É fundamental estabelecer o diálogo e a escuta das necessidades dos grupos atendidos, através de um olhar transpessoal do indivíduo e do coletivo. Portanto, se faz necessário ponderar a sustentabilidade das ações de saneamento e como poderiam ser esses dispositivos para produção e incorporação de subjetividade, indo no sentido de uma ressignificação individual e coletiva, ao invés da utilização de tecnologias hegemônicas para atender situações, territórios e indivíduos diferentes ${ }^{1}$.

Assim, é de suma importância integrações estruturais de implantação efetiva de tecnologias sanitárias no campo, e estruturantes, de educação e mobilização social, produzindo uma nova subjetividade para os envolvidos, ampliando o leque de saneamento e saúde comum para uma abordagem que contemple também as questões mentais e emocionais.

\section{As Três Ecologias}

A urgência por transformações traz a necessidade de mudanças nas visões coletivas de mundo e na forma de atuação para cuidar do meio ambiente. Um dos pontos primordiais a ser aprofundado é o conceito introjetado de meio ambiente, no qual o homem não se vê integrado e pertencente à natureza. $\mathrm{O}$ olhar cartesiano dissociou a sabedoria, separando o observador do observado, a natureza do ser humano, a cultura da natureza ${ }^{1}$. O antropocentrismo entende a natureza como um bem a ser utilizado e a caracteriza como meio ambiente. Assim, transforma-se a natureza em uma forma de capital a ser utilizado ou restaurado de acordo com a necessidade. É exatamente essa sensação de separatividade que dificulta o estabelecimento de uma relação afetiva e um cuidado efetivo com o meio ambiente, percebendo o ser humano integrado a natureza. Segundo Moscovici ${ }^{9}$, o homem não pode ser visto separadamente do ambiente em que está inserido. Logo, quando se cuida apenas da natureza, sem considerar a comunidade e o indivíduo no território, promove-se exclusão social.

A abordagem de "ecoeficiência" como um caminho para o desenvolvimento sustentável exemplifica essa dissociação na prática. Essa visão acabou dominando debates ambientais, sociais e políticos, introduzindo soluções para "ganho econômico e ecológico", mantendo a cultura hegemônica da natureza como um capital de ven$\mathrm{da}^{10}$. Embora as ações nesse formato apresentem impactos positivos na preservação dos recursos ambientais, não consideram integralmente as questões sociais do território, incidindo apenas sobre os pilares econômico e ambiental, negligenciando o psicossocial.

A dissociação entre ser humano e natureza nas intervenções ambientais pode ser vista na criação de Parques Nacionais, em que geralmente são precedidas ou seguidas pelo deslocamento ou expulsão de populações nativas, ignorando o papel que essas populações desempenham na conservação do meio ambiente em que vivem ${ }^{11}$. Além disso, o saber tradicional é desconsiderado e muitas vezes as comunidades são marginalizadas por meio de legislações que desmerecem seus modos de bem viver. A partir deste olhar, pode-se compreender a relação de simultaneidade entre a destruição da natureza e a destruição da cultura, ou seja, o "ecocídio" é, em certos aspectos, um "etnocídio", que se dá pela desconsideração da cultura local ${ }^{9}$.

O conceito de "justiça ambiental" prioriza o protagonismo das populações marginalizadas e suas condições de vida, ressaltando a importância da autonomia, sustentabilidade e equidade no atendimento das necessidades dos povos nativos $^{12}$. Vale ratificar que para fomentar ações de saneamento em comunidades isoladas ou tradicionais e promover "justiça ambiental” é fundamental um olhar que considere não só as normas e as tecnologias disponíveis, mas principalmente as dimensões ecológicas, sociais, econômicas e individuais em cada território.

Para isso, convém compreender e diferenciar as Tecnologias Convencionais (TC) das Tecnologias Sociais (TS). Em síntese, as TC são ambientalmente insustentáveis, alienantes, hierarquizadas e detentoras de controles coercitivos que diminuem a produtividade. Esse tipo de tecnologia hegemônica não considera o contexto local, social, a natureza e os seres humanos envolvidos no processo.

As Tecnologias Sociais (TS), por sua vez, são consideradas adaptadas, com sistemas não convencionais, apresentando uma alternativa à visão habitual, promovendo a emancipação social ${ }^{13}$. O conceito adotado pela Rede de Tecnologia Social (RTS) é: "tecnologia social são técnicas e metodologias transformadoras, desenvolvidas na interação com a população, que representam soluções para inclusão social ${ }^{14 "}$. As TS, em sínte- 
se, são: i) adaptadas a pequeno tamanho físico e financeiro; ii) não discriminatória nas relações de trabalho; iii) orientada para o mercado interno de massa; iv) liberadora do potencial e da criatividade e v) capaz de viabilizar economicamente os empreendimentos autogestionários e as pequenas empresas ${ }^{13}$. Essas tecnologias têm sido enfatizadas no Brasil nos movimentos sociais e, mais recentemente, na forma de políticas públicas $^{15}$ e no campo de saneamento.

\section{A Ecologia Ambiental}

A questão natural se origina na crise do lugar da humanidade na natureza, a partir de uma cisão, da sensação de separatividade vivenciada em suas relações. Para estabelecer novos paradigmas de interconexão, é primordial regressar à natureza, o que significa voltar com nossos corpos ao corpo dos corpos, a terra, onde cada um encontra sua morada ${ }^{9}$, focando na relação de interação entre o ser humano e a natureza, em sua interdependência e integração. O ser humano é um ser sistêmico e, assim como a sociedade e o planeta, funciona integrado com a natureza ${ }^{16}$.

Para isso, ecologistas e cientistas devem andar lado a lado, afinal, o estabelecimento de um método científico ou técnico deve depender não apenas da eficiência tecnológica obtida, mas também da avaliação de suas vantagens e efeitos negativos: psíquicos, físicos e sociais. O olhar crítico dos ecologistas é imprescindível, para se manter, em primeiro lugar, o respeito à vida ${ }^{9}$. Seu foco se fundamenta justamente na regra da reciclagem aplicada a não somente aos materiais, mas igualmente às ideias e às formas de vida.

Nesse cenário, o saneamento tem sido revisitado através do uso de TS, com desenvolvimento de ações de saneamento ecológico. O denominado saneamento ecológico representa uma visão alternativa da economia ambiental neoclássica em relação à sustentabilidade dos atuais padrões de desenvolvimento e promove o correto manuseio e uso dos dejetos humanos e de animais como produtos, garantindo a segurança sanitária e fechando o ciclo dos nutrientes ${ }^{17}$, de forma mais integrada à natureza e às condições sociais de cada território.

Em suma, a diferença é que enquanto os sistemas convencionais de saneamento são lineares, tratando o efluente e descartando-o na natureza, os sistemas de saneamento ecológico reutilizamno, através da modificação e aproveitamento do ciclo de nutrientes do mundo natural ${ }^{18-21}$, possibilitando a recuperação de macro e micronu- trientes, matéria orgânica, água e energia contidos nas águas residuais. Há também a segregação na fonte, ou seja, a separação das águas negras (oriundas do vaso sanitário) das águas cinzas (não contaminadas com fezes), que permite o tratamento prático e descentralizado dos diferentes tipos de efluentes domésticos e a diluição mínima dos fluxos, ou seja, aumento da disponibilidade hídrica pela economia e reuso de água, a proteção dos recursos hídricos pelo não lançamento de esgoto - tratado ou não - nos cursos de água, aumentando as concentrações dos recursos a serem aproveitado ${ }^{20-23}$. O tratamento das águas cinzas é relativamente simples, dependendo do objetivo do reuso, podendo ser feito nas próprias residências com aplicação direta no solo, para irrigação de árvores e jardins, desde que sejam seguidos alguns critérios de ordem sanitária ${ }^{24}$. Ainda, essas águas representam $70 \%$ do esgoto doméstico ${ }^{25}$. O uso de tanque de evapotranspiração para águas negras, exemplo de TS, apresenta potencial para reaplicação em condomínios populares e zonas rurais, e pode ser utilizada como jardim, próxima as residências, ainda havendo o benefício de gerar frutos ${ }^{18,22,25}$.

O TEVAP usa o esgoto como nutriente para o solo. Trata-se de câmara única e selada, tipo prismática, medindo em média, $2 \mathrm{~m}$ de largura $\mathrm{x} 5 \mathrm{~m}$ de comprimento $\mathrm{x} 1,6 \mathrm{~m}$ de altura. No seu intetior existe: uma câmara séptica feita de tijolos cerâmicos furados, formando espécie de pirâmide, ou pneus em série, onde ocorre a etapa de digestão anaeróbia, seguida de um meio poroso de multi-camadas para filtração (entulho, brita, areia, em série); zona de raízes para absorção dos nutrientes e da água pelos vegetais. Finalmente, fechando os ciclos, o sistema produz frutos (bananas) e retorna a água para a atmosfera, por meio da evapotranspiração ${ }^{18}$.

O Quadro 1 foi criado a partir das referências bibliográficas consultadas.

Além disso, a perspectiva de inclusão social no processo relativo à tomada de decisão e nas etapas construtivas traz uma nova conexão do ser humano com a natureza e fomenta uma ecologia ambiental, ou seja, o surgimento de uma nova consciência ambiental na prática. Como abordado por Freire ${ }^{2}$, é a partir da compreensão do ser humano se perceber implicado e integrado com a natureza, a partir da práxis, que ocorre uma conscientização capaz de gerar novos impulsos alinhados ao cuidado com os sistemas.

Originadas na interação entre ecologistas e ativistas, muitas destas novas práticas têm sua validade acadêmica questionada por apresentarem 
Quadro 1. Comparação do saneamento convencional com o saneamento ecológico. Fonte: própria.

\begin{tabular}{|c|c|}
\hline Saneamento Básico & Saneamento Ecológico \\
\hline Ações de prevenção de doenças e controle da poluição. & Ações preventivas de doenças e de promoção da saúde. \\
\hline $\begin{array}{l}\text { Consiste no tratamento e adequação dos padrões da } \\
\text { legislação para disposição final do efluente, de forma } \\
\text { adequada. }\end{array}$ & $\begin{array}{l}\text { É sustentável, socialmente aceito e economicamente } \\
\text { viável. }\end{array}$ \\
\hline $\begin{array}{l}\text { Considera majoritariamente os aspectos técnico/ } \\
\text { econômicos. }\end{array}$ & $\begin{array}{l}\text { Considera os aspectos sociais, ambientais, técnico/ } \\
\text { econômicos e culturais }{ }^{19} \text {. }\end{array}$ \\
\hline $\begin{array}{l}\text { Considera os dejetos e águas residuais como rejeitos, } \\
\text { que devem ser tratados e dispostos adequadamente. }\end{array}$ & $\begin{array}{l}\text { Considera dejetos e águas residuais como recursos, } \\
\text { que devem ser reaproveitados, protegendo assim os } \\
\text { recursos naturais }{ }^{20,23} \text {. }\end{array}$ \\
\hline $\begin{array}{l}\text { Não há separação das águas. Assim o tratamento é } \\
\text { realizado unificadamente. }\end{array}$ & $\begin{array}{l}\text { Separa a água em dois tipos: águas negras (águas } \\
\text { de sanitário) e águas cinzas, para posterior } \\
\text { aproveitamento } \\
\end{array}$ \\
\hline $\begin{array}{l}\text { Trata o ciclo dos nutrientes e da água de forma linear, } \\
\text { aberta. }\end{array}$ & $\begin{array}{l}\text { Promove o fechamento do ciclo dos nutrientes e da } \\
\text { água com seu reaproveitamento }{ }^{20} \text {. }\end{array}$ \\
\hline Caracterizado como Tecnologia Convencional. & Caracterizado como Tecnologia Social (TS). \\
\hline Construído a técnica de forma convencional. & $\begin{array}{l}\text { Construído a técnica considerando as dimensões } \\
\text { socioambientais e culturais locais. }\end{array}$ \\
\hline $\begin{array}{l}\text { Construído para a população, enquanto beneficiária } \\
\text { passiva. }\end{array}$ & $\begin{array}{l}\text { Construído com a população, de forma a gerar } \\
\text { autonomia, tendo o sujeito de direitos ativo nos } \\
\text { territórios. }\end{array}$ \\
\hline $\begin{array}{l}\text { Conduzidos por técnicos sem participação } \\
\text { comunitária. }\end{array}$ & $\begin{array}{l}\text { Conduzidos em dialogo e com participação } \\
\text { comunitária }\end{array}$ \\
\hline Treinamentos curtos e rápidos. & $\begin{array}{l}\text { Processos de capacitação e de educação em saúde, com } \\
\text { educação popular, partilhas construtivas, rodas de } \\
\text { conversa, dentre outras. }\end{array}$ \\
\hline Prioriza a informação individualizada & $\begin{array}{l}\text { Prioriza a formação coletiva e a mobilização social } \\
\text { educadora }\end{array}$ \\
\hline $\begin{array}{l}\text { É instrumental e atemporal, baseada na solução } \\
\text { técnica }\end{array}$ & $\begin{array}{l}\text { É parte e expressão dos arranjos comunitários e se } \\
\text { fortalece em redes sociais }\end{array}$ \\
\hline
\end{tabular}

apenas dados empíricos das soluções implementadas. Contudo, ao invés de cerceá-las, a academia deveria aprofundar-se nelas para avaliar seus resultados, otimizar e aprimorar seus processos. Cabe valorizar o campo da experimentação social, pois é uma prática que transforma.

Diversos ativistas e pesquisadores já estão fundamentando esses novos conceitos e ações baseados na práxis e em uma nova relação do homem com a natureza ${ }^{17,18,22,26-29}$. Tais ações apresentam ganhos técnicos, ao mesmo tempo em que focam nas questões socioambientais e corroboram com a necessidade da construção de projetos que integrem ações estruturais (investimentos em obras e infraestrutura) e estruturantes (ações de educação, participação e mobilização social) de saneamento conjugadas e direcionadas ao desenvolvimento de uma nova atuação socioambiental, ancorada na compreensão e interna- lização da relação interdependente ser humano e natureza ${ }^{30}$.

O fomento de ações e pesquisas aplicadas na sistematização de conhecimentos no campo de saneamento ecológico se torna essencial para propiciar às comunidades rurais e tradicionais opções humanizadas e fundamentadas academicamente $^{8}$. Inclusive, a sistematização nesse campo pode propiciar novas possibilidades de financiamento de recursos públicos e direcionamento de orçamento para atender ao ODS6, de universalização de saneamento, por meio de ações mais adequadas às necessidades territoriais.

\section{A Ecologia Social}

Como já abordado anteriormente, não se pode separar a natureza da cultura e precisamos aprender a pensar transversalmente as interações 
entre ecossistemas e Universos de referências sociais e individuais ${ }^{1}$. Uma gestão coletiva/participativa e uma autorresponsabilidade se impõem para orientar as ciências e as técnicas em direção a finalidades mais humanas. Neste sentido, não é justo separar a ação sobre a natureza daquela sobre o socius, seu conjunto de valores referentes à comunidade e à psique de seus sujeitos. Quando visualizamos o saneamento através da ecologia social, seu princípio diz respeito à promoção de um investimento afetivo em grupos humanos de diversos tamanhos. $\mathrm{O}$ desafio consiste em desenvolver práticas específicas que tendam a modificar e reinventar maneiras de ser nos diversos contextos e coletivos, reconstruindo o conjunto de modalidades do ser em grupo. Para isso é necessário focar nos modos de produção de subjetividade: de conhecimento, cultura, sensibilidade e sociabilidade, que se relacionam com a produção de novos símbolos nos coletivos relacionados com o cuidado humano.

Para este tipo de troca e mudança simbólica social, os projetos devem promover diálogo e trocas entre todos os atores, com o envolvimento integral dos grupos atendidos no território, de forma horizontal através de uma ecologia de saberes, gerando autonomia individual e coletiva ${ }^{31,32}$.

A ecologia de saberes confronta a monocultura da ciência moderna, porque se baseia no reconhecimento da pluralidade de conhecimentos heterogêneos (sendo um deles a ciência moderna) e em interações sustentáveis e dinâmicas entre eles sem comprometer a sua autonomia. Assim, seu intuito é cruzar conhecimentos e, portanto, também ignorâncias. Busca dar credibilidade aos conhecimentos não científicos, o que não implica o descrédito do conhecimento científico, mas, simplesmente, a sua utilização contra-hegemônica. E é exatamente por isso que o uso contra-hegemônico da ciência não pode limitar-se à ciência. Sua definição expande o caráter testemunhal dos conhecimentos de forma a abarcar igualmente as relações entre o conhecimento científico e o não científico, alargando deste modo o alcance da inter-subjetividade como interconhecimento e vice-versa ${ }^{31}$.

Moscovici ${ }^{9}$ corrobora com a visão de ecologia de saberes ao abordar como importante estratégia o "ganhar nas margens", ou seja, envolver todos os atores possíveis, ocupando espaços atualmente mudos em nossa sociedade e deixar as ideias das minorias penetrarem na ecologia e a ecologia nas suas. Hoje, assistimos a um florescimento de minorias ativas que remodelam o mapa de nossa sociedade.
Ao atuar coletivamente em cada território podemos reinventar e adaptar as tecnologias, considerando todas as vozes envolvidas no processo para garantir a horizontalidade e a equidade. Para realizar mudanças efetivas, é importante aproveitar a diversidade como estratégia dos sistemas vivos para maior resiliência, promovendo autonomia local e empoderamento de grupos de congruência ${ }^{33,34}$.

Levando-se em conta as questões tratadas, para se alcançar a ecologia social e uma mudança simbólica efetiva é relevante atuar no território, sempre envolvendo o grupo local nas ações efetivas, para conhecer as necessidades vivas e promover uma integração da cultura local em relação ao saneamento.

A utilização de pesquisa-ação promove um olhar holístico para a implementação da TS, considerando a técnica, o contexto do território e a população atendida e um dos seus principais objetivos consiste em dar aos pesquisadores e participantes os meios para responderem com maior eficiência aos problemas da situação em que vivem a partir de diretrizes de ação transformadoras. Trata-se de facilitar a busca de soluções aos problemas reais para os quais os procedimentos convencionais têm pouco contribuído. Neste sentido, os procedimentos a serem escolhidos devem obedecer a prioridades estabelecidas a partir de um diagnóstico da situação no qual os participantes tenham voz e vez ${ }^{35}$.

Sem dúvida, a pesquisa-ação exige uma estrutura de relação entre pesquisadores e pessoas da situação investigada que seja participativa. Assim, é estabelecida uma horizontalidade na relação facilitador/comunitário através da valorização de aspectos qualitativos, grupais e informacionais do sistema pesquisado ${ }^{36}$.

Do ponto de vista sociológico, a proposta de pesquisa-ação dá ênfase à análise das diferentes ações. Dessa forma, a mesma não pretende focar na psicologia individual e, também, não é adequada ao enfoque macrossocial. Ela se configura como um instrumento de trabalho e de investigação com coletivos de pequeno e médio porte. Contrariamente a certas tendências da pesquisa psicossocial, os aspectos sociopolíticos são mais pertinentes do que os psicológicos das relações intrapessoais. Contudo, essa visão não despreza a realidade psicológica e seus valores ${ }^{35}$. Assim, a pesquisa-ação é considerada um método ou uma estratégia de pesquisa e ação que agrega várias técnicas de pesquisa social.

Para um melhor entendimento das demandas populares em pesquisa-ação são exigidos proces- 
sos elaborados para compreender sua realidade, como a pesquisa social qualitativa, reconhecida tanto por sua capacidade de captar elementos simbólicos como também por trabalhar melhor a relação observador-observado. Esta abordagem trabalha com o universo de significados, motivos, aspirações, crenças, valores e atitudes. A realização de uma pesquisa social empírica compreende a articulação de diversas técnicas como a observação participante, entrevistas grupais ou individuais, grupo focal, diagnóstico participativo, levantamento de dados secundários de caráter quantitativo e pesquisa bibliográfica sobre o tema. Para a análise desses dados, utiliza-se a triangulação, que permite seu encadeamento e validação, propiciando uma inserção profunda no contexto do qual emergem as falas, os fatos e as ações dos indivíduos ${ }^{8}$.

A proposta metodológica apresentada constitui-se como uma possibilidade de intervenção integrada, na qual várias ferramentas podem ser combinadas para atingir os objetivos pretendidos, colaborando na introdução de um diálogo entre culturas e grupos sociais, aceitando-se a crítica ao relativismo cultural desenvolvida por Boaventura Sousa Santos ${ }^{8}$.

Observa-se que no decorrer do processo os aspectos argumentativos são articulados, principalmente, em situações comunicacionais, de diálogo entre pesquisadores e participantes. Nestes casos é estabelecida uma "comunidade de espíritos" ou um "vínculo intelectual", com o intuito de se chegar ao consenso acerca da descrição de uma situação e a uma convicção a respeito do modo de agir. Contudo, é de grande interesse estudar as diferenças de linguagem, destacando aquelas que são obstáculos à intercompreensão, pois não se trata apenas dos participantes aceitarem pontos de vista ou noções que não pertenciam ao seu universo de representações. Os próprios especialistas podem alterar a sua própria representação no sentido de complementar o conteúdo em que já tinham experiência de outra forma ${ }^{35}$. Um modo de ampliar os resultados de uma pesquisa-ação é focar em mecanismos de comunicação que propiciem a cada indivíduo verbalizar a sua verdade para coconstruir sentidos compartilhados, que sejam inclusivos e gerem pertencimento a todos os envolvidos, através de uma ecologia de sentidos.

\section{A Ecologia Mental}

Quando se trabalha com coletividades, a ecologia mental indica que deve-se atuar na recons- trução das relações humanas em todos os níveis do socius, ou seja, sobre o conjunto de valores referentes à comunidade e sobre a psique de seus indivíduos. Não se deve desconsiderar que o poder capitalista se deslocou, se desterritorializou, infiltrando-se nos mais inconscientes estratos subjetivos, do macro ao micro.

Logo, um dos problemas-chave entre a ecologia social e a mental é a introjeção do poder repressivo por parte dos oprimidos. Os próprios defensores dos interesses dos oprimidos reproduzem em suas relações íntimas os mesmos modelos patogênicos que entravam a liberdade de expressão e inovação ${ }^{1}$. Não é possível se opor ao capitalismo apenas externamente, através de práticas sociais e políticas tradicionais. É imperativo encarar esses efeitos no domínio da ecologia mental dos indivíduos abrangidos, pois a partir dessa percepção é crucial cultivar o dissenso e a produção singular de existência. Philippi ${ }^{8}$ traz uma visão complementar ao defender que o próprio indivíduo é recriado pela sua representação do mundo. Dessa forma, para analisar um indivíduo é importante considerar seu contexto na estrutura social em que pertence, assumindo elementos de cultura, da linguagem e das representações do grupo no qual está inserido.

Quando representantes de coletivos diversos dialogam, mesmo que por meio de uma ecologia de saberes e em espaços comunicativos nos quais pretende-se a horizontalidade, a identidade subjetiva defendida por cada um fala mais alto, apresentando divergências de visão de mundo. $\mathrm{Na}$ política os conflitos estão sempre presentes. Logo, quando essas identidades coletivas buscam defender seus conceitos, mesmo que decidindo por consenso, há sempre a exclusão de alguém ou de algo nestas concepções, o que revela uma inclinação humana pela exclusão. Se o político exclui sempre algo ou alguém, pode-se supor que o político se assemelhe à hostilidade. Assim, o campo do político configura-se pela relação entre um coletivo que se constitui como um NÓS (identidade coletiva) versus um ELES (exteriorização da identidade coletiva). Nesse sentido, temos um sujeito coletivo totalizado e fechado sobre si mesmo, em sua identidade social, e um constitutivo externo como impossibilitado de constituir-se como um possível NÓS ${ }^{37}$. No atual contexto social, para manter a identificação com suas raízes sociais, ao invés de cooperar acreditando em um NÓS, subjuga-se ELES e continua a perpetuação da cultura capitalista do oprimido/opressor.

Portanto, deve-se encontrar meios pelos quais as pessoas podem ser proprietárias de suas 
próprias vidas, tanto a partir do controle pessoal, como da influência social. O empoderamento é um processo no qual as pessoas tornam-se conscientes de si mesmas ${ }^{37}$. Uma forma importante de alinhar os diversos atores de um território é coconstruir visões de mundo que englobem ambas conceituações. Ainda, Nasciutti ${ }^{38}$ traz a percepção de que o indivíduo não pode ser estudado apenas de um ângulo e que as estruturas fazem sentido porque se organizam em função da vida individual.

Neste viés, a "ecologia de sentidos" fala que o conhecimento não está nem inscrito na mente (no sujeito), nem no mundo (o objeto), mas in media res, entre as possibilidades do sujeito interagir com o objeto por meio de processos orgânicos e simbólicos de assimilação e acomodação. A expressão latina in media res, refere-se ao lugar em que se constrói a possibilidade do conhecimento, por meio da comunicação entre os sujeitos ${ }^{39}$. A comunicação é vista como um mecanismo biológico que permite ao sujeito fazer sentido de si mesmo e do mundo exterior, afinal, qualquer movimento para o interior está correlacionado com outro para o exterior. Contudo, a ecologia dos sentidos e os métodos construtivistas-críticos permitem tanto o estudo das interações cooperativas como o das patologias comunicativas, porque levam em conta a transversalidade dos conhecimentos. Ao entender como as razões e as emoções evoluem ao longo das vidas de indivíduos imersos em grupos e sociedades cultural e historicamente construídas, Campos ${ }^{39}$ avançou na construção da teoria de ecologia de sentidos, a qual permite um olhar sobre as configurações de sentidos que emergem de construções e coconstruções de imagens do mundo expressas em produções discursivas esquematizadas.

De acordo com essa teoria, a saída cooperativa, cuja solução exige transformações ético-sociais, passa pelo diálogo e por uma revisão radical da estrutura e do funcionamento dos procedimentos democráticos, notadamente da ação do pesquisador que olha os sujeitos que comunicam no mundo ${ }^{39}$. Assim, pela criação de espaços onde se permite um diálogo genuíno e um compartilhamento de imagens de mundo, são coconstruídas novas ecologias mentais em cada indivíduo, os quais se tornam mais conscientes, empoderados e desidentificados de padrões alicerçados no capitalismo, consequentemente mais autônomos.

A partilha de sentidos e a coconstrução de uma imagem coletiva permitem que novas soluções possam emergir, considerando os aportes de cada indivíduo, os quais representam apenas uma voz da inteligência coletiva que acontece in media res.

\section{Abordagem integral}

A partir das proposições de Guattari ${ }^{1}$ e das linhas teóricas da psicossociologia propõe-se uma forma de atuação que contemple as múltiplas facetas dos atores envolvidos no processo. A Figura 1 apresenta essa abordagem integral.

Com a abordagem integral, as tecnologias podem ser implementadas através de um ponto de vista que contemple a reconexão dos indivíduos com a natureza, com seus coletivos e consigo mesmos. Conclui-se, portanto, que esse tipo de abordagem é necessária na implementação de ações efetivas no campo do saneamento por promover uma ecologia ambiental, reconexão com a natureza e seus processos de transformação; uma ecologia social, promovendo a inclusão dos grupos atendidos através da valorização e incorporação de todos os saberes inerentes à questão; e uma ecologia mental, com diálogo efetivo e respeito à singularidade de cada individuo.

É importante ratificar a necessidade de um olhar expandido para propiciar a cooperação intrassetorial e intersetorial: agentes facilitadores, comunitários, órgãos públicos, órgãos ambientais fiscalizadores, órgãos financiadores e sociedade civil. Assim, a sinergia da ecologia de saberes amplia os resultados obtidos no território. Por sua transversalidade, o diálogo perpassa todas as dimensões, e religa cada ser humano à sua visão de mundo, propiciando o contato interno do indivíduo consigo mesmo. A troca de sentidos entre os indivíduos faz brotar novas imagens de mundo: mais inclusivas, coconstruídas por todos, promovendo a sensação de pertencimento e estabelecendo condições de cooperação. Ainda, este contato com diversas visões de mundo, permite a cada indivíduo refletir sobre sua atuação identificada com os coletivos e se desidentificar da tradicional abordagem oprimido-opressor, podendo agir como um ator social, otimizando resultados e aproximando cada ser humano.

Logo, em projetos de saneamento, quando se apresentam metodologias para integrar a ecologia de saberes e de sentidos, além da comunicação direta pelo compartilhamento de visões de mundo, são importantes outras abordagens para a comunicação não verbal a fim de promover novas formas de compreensão dentro de todos os envolvidos.

O Plano Nacional de Saneamento Básico (PLANSAB $^{40}$ traz inovações em sua formula- 


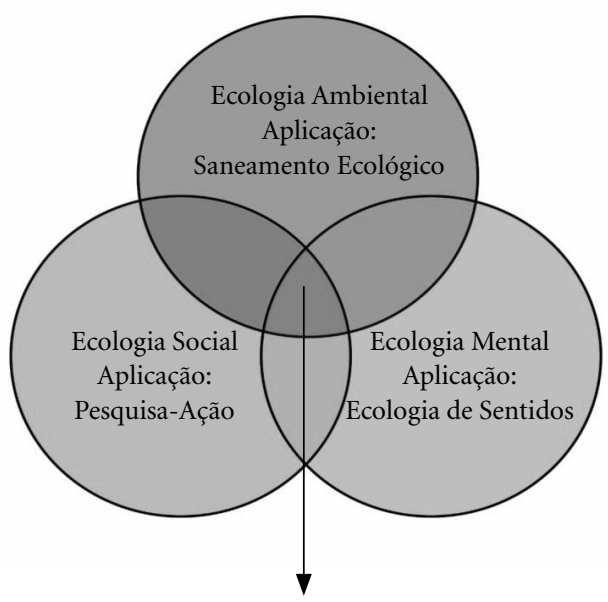

Abordagem Integral Aplicada ao Saneamento

Figura 1. Abordagem Integral para saneamento em comunidades rurais e tradicionais.

Fonte: Própria.

ção que possibilitam ações efetivas e transversais alinhadas com a ecologia tripla de Guattari ${ }^{1}$ e a abordagem integral apresentada. Ainda, como apontado no Programa Nacional de Saneamento Rural (PNSR ${ }^{41}$, que vem sendo construído de forma participativa desde 2016, para alcançar áreas rurais são considerados os seguintes eixos estratégicos: (i) Gestão dos Serviços; (ii) Educação e Participação Social; (iii) Tecnologia, que estão interconectados no mundo prático ${ }^{41}$.

No Brasil, atualmente estão sendo aplicadas diversas TS de saneamento ecológico ainda não certificadas, tais como biodigestores para geração de gás, tanques de evapotranspiração, fossas biodigestoras, filtros de água cinza, banheiros secos, entre outros. A Fundação Banco do Brasil ${ }^{42}$ já certificou 10 experiências neste campo, tendo exemplos como: i) "De olho na água (Ceará); ii) utilizando metodologias participativas na construção de Agroecologia (Minas Gerais) e Filtragem de jardins - sistema de saneamento ecológico (Rio Grande do Sul); e iii) filtros de águas cinzas construídos pelo Instituto de Permacultura e Educação Caiçara (IPECA), o que mostra a relevância do fortalecimento de estudos e ações no campo do saneamento rural ${ }^{42}$. Cabe reforçar que as ações devem ser estabelecidas para atender os interesses e as necessidades do território e que as partes interessadas devem ser consultadas ${ }^{43}$ e incluídas.

Como apontado acima, já é destacado na legislação e em conjuntura nacional, que as TS para saneamento adaptadas ao território contribuem para a capacitação e a perpetuação das comunidades tradicionais em seus territórios. Cabe ressaltar que essa abordagem integral foi desenvolvida e implementada, para construção coletiva de TS de saneamento ecológico, utilizando a tecnologia de TEVAPs ${ }^{18}$, em uma pesquisa-ação, com contratação dos construtores da comunidade como mobilizadores sociais ${ }^{44}$ e o desenvolvimento de educomunicação ambiental ${ }^{45}$, de 2014 a 2018, junto com a Comunidade Caiçara da Praia do Sono e o Fórum de Comunidades Tradicionais de Angra dos Reis, Paraty e Ubatuba (FCT), a partir do projeto Observatório de Territórios Sustentáveis e Saudáveis da Bocaina (OTSS/Fiocruz $)^{18,44,45}$. Pode-se constatar em quatro anos de pesquisa-ação, que utilizar uma abordagem integral para saneamento promove mudanças na consciência dos indivíduos e fomenta uma conscientização, uma ação diferenciada ao longo de todo o processo, inferindo mudanças não apenas na comunidade mas nos atores locais.

Sendo assim, a pesquisa-ação ${ }^{18,44,45}$ apresentada, no que tange à capilarização e construção de soluções territorializadas, convergindo saberes tradicionais, permacultura e engenharia, a partir de uma abordagem integral, se mostrou eficiente ao longo do processo, em fomentar e dialogar com o campo das políticas públicas para estimular e apresentar práticas de saneamento ecológico que possam ser reaplicadas. Assim, buscou-se 
fomentar para além de pesquisas, ações que possam ser reaplicadas e que promovam desenvolvimento real na sociedade.

\section{Conclusão}

A abordagem integral apresentada e implementada em comunidade tradicional mostrou que se pode favorecer o diálogo nas diversas dimensões: o saneamento ecológico pode propiciar um religar e o diálogo do ser humano com a natureza; a pesquisa-ação e a ecologia de saberes fomentam o diálogo entre os diversos atores coletivamente; a ecologia dos sentidos e seus desdobramentos concedem a formação de novas visões de mundo dentro de cada indivíduo, o que impacta na ecologia mental, gerando desidentificação do coletivo, uma maior autonomia de reflexão e consequentemente uma maior disponibilidade para cooperação.

Como apontado ao longo deste artigo, o saneamento, ainda abordado de forma exógena, deve abarcar os conhecimentos tradicionais para manejo das águas a partir de uma ecologia de saberes efetiva. Além de cuidar da natureza, é uma importante ação de promoção da saúde. A abordagem transversal tem o potencial de promover impactos positivos em diversos aspectos da saúde como o social, o econômico e o mental, garantindo a sustentabilidade e fomentando a equidade e a autonomia das populações atendidas. Cabe ainda ressaltar que a equidade é um dos maiores objetivos de ação apontados pela ONU para reduzir desigualdades e garantir qualidade de vida.

Assim, este estudo revela um caminho efetivo com a utilização do saneamento ecológico como metodologia de aplicação, apoiada pela pesquisa -ação, pela ecologia de saberes e pela ecologia de sentidos, a fim de promover a inclusão de todos os atores envolvidos horizontalmente, um olhar singular para o desenvolvimento de uma nova consciência através da "práxis" e da construção de sentidos coletivos. Logo, no trabalho com comunidades tradicionais e rurais, é fundamental a utilização de tecnologias sociais, inclusivas, eficientes e de baixo custo, que possam ser assimiladas e replicadas pela população atendida.

Conclui-se que a adoção de uma abordagem integral: transversal e intersetorial, para saneamento e projetos comunitários, apresenta caminhos mais inclusivos e adequados ao território e promove uma maior satisfação e aprendizado para todos os envolvidos, a partir da compreensão de que, sozinhos, sabemos muito pouco.

Neste sentido, uma ecosofia, que embaralhe e integre a tripla visão ecológica, deve e pode substituir as antigas formas de engajamento associativo, promovendo processos de subjetivação e ressingularização que permitam aos indivíduos se tornarem a um só tempo solidários e cada vez mais diferentes.

\section{Colaboradores}

GCXMP Machado participou da concepção, redação, levantamento de dados e análise a partir de sua pesquisa de doutoramento. TMFB Maciel e M Thiollent participaram da concepção, redação e análise crítica na condição de orientadores. 


\section{Referências}

1. Guattari F. As Três Ecologias. Campinas: Papirus; 1990.

2. Freire P. Conscientização. São Paulo: Cortez; 2016.

3. Gallo E, Setti AFF. Território, Intersetorialidade e Escalas: Requisitos para a Efetividade dos Objetivos de Desenvolvimento Sustentável. Cien Saude Colet 2014; 19(11):4383-4396.

4. Organização das Nações Unidas (ONU). El futuro que queremos. 2012. [acessado 29 Jan 2016]. Disponível em: http://www.uncsd2012.org/content/documents/ 778futurewewant_spanish.pdf

5. United Nations University Institute for Water, Environment and Health (UNU-INWEH). Sanitation as a Key to Global Health: Voices from the Field. 2010. [acessado 24 Set 2016]. Disponível em: http://www.bvsde. paho.org/texcom/cd045364/sanitationkey.pdf.

6. Heller L. Saneamento e Saúde. Brasília: OPAS/OMS; 1997.

7. Intergovernmental Panel on Climate Change (IPCC). IPCC Climate Change 2014: Impacts, Adaptation, and Vulnerability. Cambridge, New York: Cambridge University Press; 2014.

8. Philippi A. Saneamento, Saúde e Ambiente: fundamentos para um desenvolvimento sustentável. Barueri: Manole; 2005.

9. Moscovici S. Para pensar a ecologia. Rio de Janeiro: Mauad X, Instituto Gaia; 2007.

10. Jänicke M. Modernização ecológica e política em sociedades industriais desenvolvidas. In: $\mathrm{Na}$ politica ambiental como um processo de modernização. Wiesbaden: VS; 1993. p. 15-29.

11. Alier MJ. O Ecologismo dos Pobres: conflitos ambientais e linguagem de valoração. São Paulo: Contexto; 2007.

12. Rede Brasileira de Justiça Ambiental (RBJA) 2010. [acessado 24 Ago 16]. Disponível em: http: www. justicaambiental.org.br/_justicaambiental/pagina/ phd?id $=2300$

13. Dagnino R. A tecnologia social e seus desafios. In: Tecnologia social: uma estratégia para o desenvolvimento. Rio de Janeiro: FBB; 2004. p. 187-209.

14. Bava SC. Tecnologia social e desenvolvimento local. In: Seidl D, Cabral SS, organizadores. Tecnologia social: uma estratégia para o desenvolvimento. Rio de Janeiro: FBB; 2004. p. 103-116.

15. Dias AP. Tecnologias sociais em saneamento e educação para o enfrentamento das parasitoses intestinais no Assentamento 25 de Maio, Ceará [tese]. Rio de Janeiro: Fiocruz; 2017.

16. Capra F. A Teia da Vida. São Paulo: Cultrix; 1997.

17. Fonseca AR. Tecnologias sociais e ecológicas aplicadas ao tratamento de esgotos no Brasil [dissertação]. Rio de Janeiro: Fiocruz; 2008.

18. Gallo E, Setti AFF, Ruprecht T, Sobrinho FX, Finamore P, Shubo T, Machado GCXMP. Territorial Solutions, Governance and Climate Change: Ecological Sanitation at Praia do Sono, Paraty, Rio de Janeiro, Brazil. Climate Change Management. Berlin: Springer International Publishing; 2016. p. 515-532.

19. Hu M, Fan B, Wang H, Qu B, Zhu S. Constructing the ecological sanitation: a review on technology andmethods. J Clean Prod 2016; 125:1-21.

20. Werner C, Panesar A, Rüd SB, Olt CU. Ecological sanitation: Principles, technologies and Project examples for sustainable wastewater and excreta management. Desalination 2008; 248(1):392-401.
21. Nicolao JN. Tecnologias de saneamento ecológico para o Tratamento de esgoto doméstico [dissertação]. Niterói: Universidade Federal Fluminense; 2017.

22. Galbiati AF. Tratamento domiciliar de águas negras através de tanque de evapotranspiração [dissertação]. Campo Grande: Universidade Federal de Mato Grosso do Sul; 2009.

23. Winblad U, Simpson-Hébert M. Ecological Sanitation. Stockholm: Stockholm Environment Institute; 2004.

24. Ridderstolpe P. Introduction to greywater management. Stockholm: Eco San Res Programme; 2004

25. Paulo PL, Azevedo C, Begosso L, Galbiati AF, Boncz MA. Natural systems treating grey water and blackwater on-site: Integrating treatment, reuse and landscaping. Ecol Eng 2012; 50:95-100.

26. Pamplona $S$, Venturi M. Esgoto à flor da terra. Permacultura Brasil. Soluções ecológicas 2004; 16:12.

27. Pinheiro LS. Proposta de Índice de Priorização de Áreas Para Saneamento Rural: Estudo de Caso Assentamento 25 de Maio, CE [dissertação]. Fortaleza: Universidade Federal do Ceará; 2011.

28. Coelho CF. Impactos socioambientais e desempenho do sistema fossa verde no assentamento 25 de maio, Madalena (CE) [dissertação]. Fortaleza: Universidade Federal do Ceará; 2013.

29. Paes WM. Técnicas de Permacultura como Tecnologias Socioambientais para melhoria na qualidade da vida em comunidades da Paraíba [dissertação]. João Pessoa: Universidade Federal da Paraíba; 2014.

30. Brasil. Ministério da Saúde (MS). Sustentabilidade das ações de saneamento rural: proposições e possibilidades para um saneamento rural sustentável - Saúde e ambiente para as populações do campo, da floresta e das águas. Brasília: MS; 2015.

31. Santos BS. Para além do pensamento abissal: das linhas globais a uma ecologia de saberes. São Paulo: CEBRAP79; 2008. [acessado em 23 Ago 16]. Disponível em: http://www.scielo.br/scielo.php?pid=S0101 $-33002007000300004 \&$ script=sci_arttext.

32. Gallo E, Setti AFF. Abordagem ecossistêmica e comunicativa na implantação de Agendas territorializadas de desenvolvimento sustentável e promoção da saúde. Cien Saude Colet 2012: 17(6):1433-1446.

33. Korten DC. The great turning: From empire to earth community. Oakland: Berrett-Koehler Publishers; 2007.

34. WeihsM, Mertens F. Os desafios da geração do conhecimento em saúde ambiental: uma perspectiva ecossistêmica. Cien Saude Colet 2013; 18(5):1501-1510.

35. Thiollent M. Metodologia da pesquisa-ação. São Paulo; Cortez: 2011.

36. Vasconcelos EM. Complexidade e pesquisa interdisciplinar - Epistemologia e metodologia operativa. Petrópolis: Vozes; 2004.

37. Prado MAM. A Psicologia Comunitária nas Américas: o Individualismo, o Comunitarismo e a Exclusão do Político. Psicologia: Reflexão e Crítica 2002, 15(1):201210.

38. Nasciutti J. Reflexões sobre o espaço da Psicossociologia. Revista Documenta 1996; 7:51-58.

39. Campos MN. Integrando Habermas, Piaget e Grize: contribuições para uma Teoria Construtivista-Crítica da Comunicação. FAMECOS 2014; 21(3):965-996. 
40. Brasil. Ministério do Meio Ambiente (MMA). PLANSAB 2013. [acessado 12 Dez 2016]. Disponível em: http://www.mma.gov.br/port/conama/processos/ AECBF8E2/Plansab_Versao_Conselhos_Nacionais_020520131.pdf

41. Plano Nacional de Saneamento Rural (PNSR) 2016. [acessado 12 Dez 2016]. Disponível em: http://www. pnsr.com.br

42. Fundação Banco do Brasil (FBB) Tecnologias Sociais Certificadas Prêmio Fundação BB de Tecnologia Social 2017.

43. Giatti LL, Rocha AA, Toledo RF, Barreira LP, Pelicioni MCF, Mutti LV, Cutolo SA. Condições sanitárias e socioambientais em Iauaretê, área indígena em São Gabriel da Cachoeira, AM. Cien Saude Colet 2007, 12(6):1711-1723.

44. Machado GCXMP, Haguenauer C, Ruprecht T, Xavier Sobrinho F, Gallo E. Ecological Sanitation: A Territorialized Agenda for Strengthening Tradicional Communities Facing Climate Change. In: Leal Filho W, Freitas LE, editors. Climate Change Adaptation in Latin America: Managing Vulnerability, Fostering Resilience. Berlin: Springer International Publishing; 2018. v. 1.: 103-129.

45. Machado GCXMP, Maciel TDFB, Carrera L, Gallo E. Environmental Educommunication and Ecology of Knowledge in the Caiçara Community of Praia do Sono, Paraty, RJ, Brazil. The International Journal of Sustainability Policy and Practice 2018; 13(4):15-31.

Artigo apresentado em 09/09/2018

Aprovado em 23/06/2019

Versão final apresentada em 25/06/2019

Editores-chefes: Romeu Gomes, Antônio Augusto Moura da Silva 